\title{
Love wave tomography in Italy from seismic ambient noise*
}

\author{
Hongyi $\mathrm{Li}^{1,2,}$ Fabrizio Bernardi ${ }^{3}$ and Alberto Michelini ${ }^{3}$ \\ ${ }^{1}$ Key Laboratory of Geo-detection (China University of Geosciences, Beijing), Ministry of Education, Beijing 100083, China \\ ${ }^{2}$ School of Geophysics and Information Technology, China University of Geosciences, Beijing 100083, China \\ ${ }^{3}$ Istituto Nazionale di Geofisica e Vulcanologia, Via di Vigna Murata 605, Rome 00143, Italy
}

\begin{abstract}
We estimate Love wave empirical Green's functions from cross-correlations of ambient seismic noise to study the crust and uppermost mantle structure in Italy. Transverse-component ambient noise data from October 2005 through March 2007 recorded at 114 seismic stations from the Istituto Nazionale di Geofisica e Vulcanologia (INGV) national broadband network, the Mediterranean Very Broadband Seismographic Network (MedNet) and the Austrian Central Institute for Meteorology and Geodynamics (ZAMG) yield more than 2000 Love wave group velocity measurements using the multiple-filter analysis technique. In the short period band (5-20 s), the cross-correlations show clearly one-sided asymmetric feature due to non-uniform noise distribution and high local activities, and in the long period band ( $>20 \mathrm{~s})$ this feature becomes weak owing to more diffusive noise distribution. Based on these measurements, Love wave group velocity dispersion maps in the 8-34 s period band are constructed, then the SH wave velocity structures from the Love wave dispersions are inverted. The final results obtained from Love wave data are overall in good agreement with those from Rayleigh waves. Both Love and Rayleigh wave inversions all reveal that the Po plain basin is resolved with low velocity at shallow depth, and the Tyrrhenian sea is characterized with higher velocity below $8 \mathrm{~km}$ due to its thin oceanic crust.
\end{abstract}

Key words: ambient noise; Love wave; tomography; crustal structure; Italy

CLC number: P315.3 Document code: A

\section{Introduction}

Surface wave tomography from cross-correlations of ambient noise instead of signals associated with ballistic source-receiver propagation has become a promising and powerful tool to study crustal and uppermost mantle structure in recent years. With ambient noise interferometry technique which is independent of earthquakes and human-made explosions, the empirical Green's function of waves traveling along the path between two receivers can be extracted from the time derivative of long-term cross-correlations (e.g., Derode et al., 2003; Weaver and Lobkis, 2004). Indeed, many applications of ambient noise surface wave tomography on both regional (e.g., Sabra et al., 2005b; Shapiro et al., 2005; Lin et al., 2007; Yao et al., 2008; Li et al., 2009; Stehly et al., 2009) and continental scales (Yang et al.,

\footnotetext{
* Received 15 March 2010; accepted in revised form 19 July 2010; published 10 October 2010.

• Corresponding author. e-mail: lih@cugb.edu.cn

(C) The Seismological Society of China and Springer-Verlag Berlin Heidelberg 2010
}

2007; Bensen et al., 2008; Liang and Langston, 2008) have recently been published, and their dispersion maps generally show higher resolution than those typically derived from earthquakes.

Italy is located between the Eurasian and African plates, which are presently converging approximately in a N-S direction. The N-S convergence between these two continental plates, active since at least $65 \mathrm{Ma}$ ago (Malinverno and Ryan, 1986; Dewey et al., 1989; Patacca et al., 1990), has resulted in a fragmentation of the lithosphere into several microplates (Westaway, 1990; Gvirtzman and Nur, 2001; Margheriti et al., 2003). The interaction among these microplates led to a very complicated tectonics, and the present-day tectonic setting of Italy is dominated by the formation of the Alps, the orogenesis of the Apennines and the opening of the Tyrrhenian basin (Patacca and Scandone, 1989). The complex tectonic setting of Italy results in strong lateral heterogeneities in the lithospheric structure (Panza et al., 1980; Mantovani et al., 1985; Pontevivo and Panza, 2002; Li et al., 2007). 
The recently installed Istituto Nazionale di Geofisica e Vulcanologia (INGV) national network, the Mediterranean Very Broadband Seismographic Network (MedNet) and the Austrian Central Institute for Meteorology and Geodynamics (ZAMG) network (Figure 1) provide dense station coverage and high-quality continuous data to perform ambient noise analysis in Italy. Thus in this study, cross-correlations from ambient noise data between October 2005 and March 2007 recorded at 114 seismic stations from INGV, MedNet and ZAMG are used to extract Love wave Green's functions. The resulting dispersion maps generally agree with the Rayleigh wave maps and show strong consistency with geological and tectonic features, and the $\mathrm{SH}$ velocity structures show significant differences of the crustal structure beneath Italy.

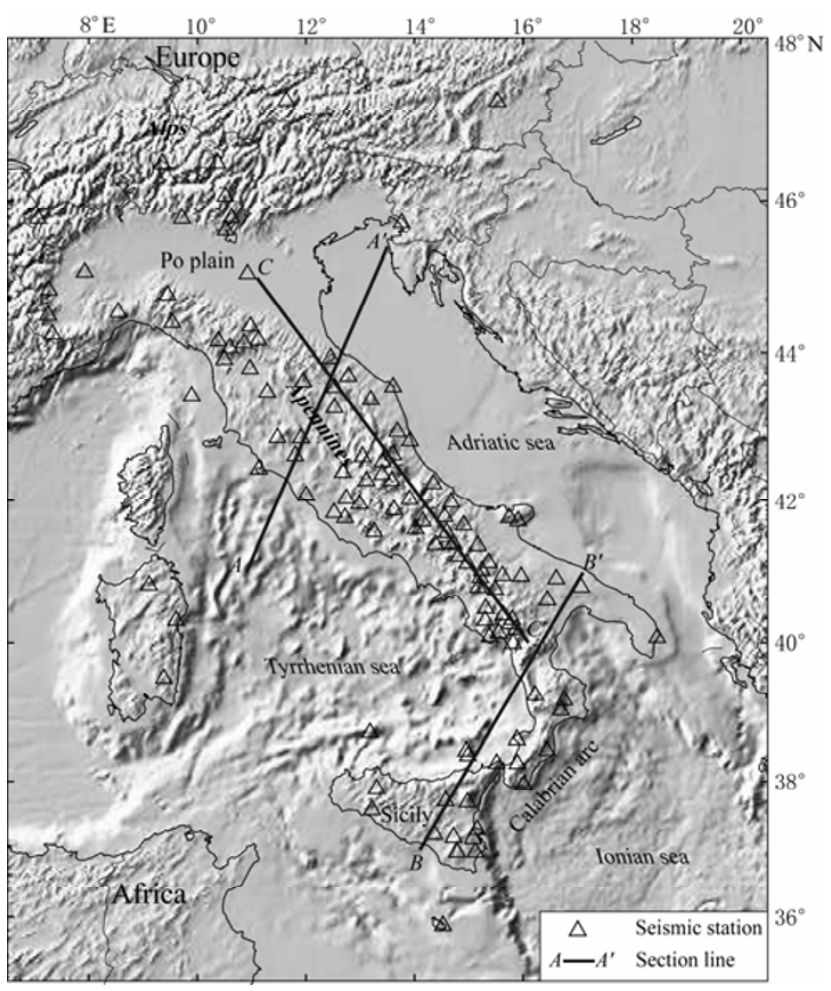

Figure 1 Geographic map of Italy and adjacent areas. Seismic stations used in this study are depicted as open triangles, and the black straight lines are the section lines of the vertical profiles $\left(A A^{\prime}, B B^{\prime}\right.$ and $\left.C C^{\prime}\right)$ shown in Figure 7.

\section{Data and group velocity measure- ments}

In this study, all data are first cut into one-hour length and the mean and trend are removed. Then data are high-pass filtered at $0.01 \mathrm{~Hz}$ and decimated to 1 sample per second. Afterward N-S and E-W components were rotated to radial and transverse components for each station-pair, and spectral whitening was applied. Transverse-component ambient noise data from October 2005 through March 2007 recorded by 114 stations from the INGV national network, MedNet and ZAMG are collected to calculate the cross-correlations between all the available station-pairs. The number of cross-correlations in the stack varies between 3 months and 1.5 years since some stations are unavailable during the period. Theoretically, with a fully diffuse wavefield or homogeneous-distributed noise sources as the ambient noise technique assumed, the resulting cross-correlations should be symmetric that positive and negative lags of correlations display the same velocity and dispersion features. In practice, asymmetric cross-correlations are often observed due to not perfectly isotropic noise distribution, and some studies have revealed that the characteristics of the seismic noise are strongly frequencydependent and direction-dependent (e.g., Pedersen et al., 2007; Marzorati and Bindi, 2008).

In Figure 2, monthly cross-correlations for three station-pairs with different azimuths and different frequency bands are given. In the short period band (0.05-0.2 Hz), one-sided cross-correlations are observed for all the three station-pairs with different azimuths, the correlation lags showing large amplitudes represent waves mainly propagating from TUE to ARSA, CING to AMUR, and CIGN to ESLN, respectively. Previous studies have shown that the noise recorded in Europe is dominated by surface waves generated along the Atlantic coast of France, the northern British coasts and the western coast of Norway (Friedrich et al., 1998; Marzorati and Bindi, 2006; Pedersen et al., 2007). Therefore the favorable directions of our correlations generally correspond to the domination of ocean-generated noise along the northern Atlantic. Meanwhile, we also noticed that the correlations for the pair ARSA-TUE show a more complex behavior; on positive lag we also observed signals with different velocity from the negative lag. The lag difference could be related to high local activities generating a wave field which propagates along a direction not aligned with the station pair direction (Marzorati and Bindi, 2008). In the frequency band 0.02-0.05 Hz, signals with contemporaneous arrivals are generally displayed on both positive and negative correlation lags which indicate that the noise field is close to diffusive in this frequency. We also observed that for the pairs CING-AMUR and ESLN-CIGN, in 

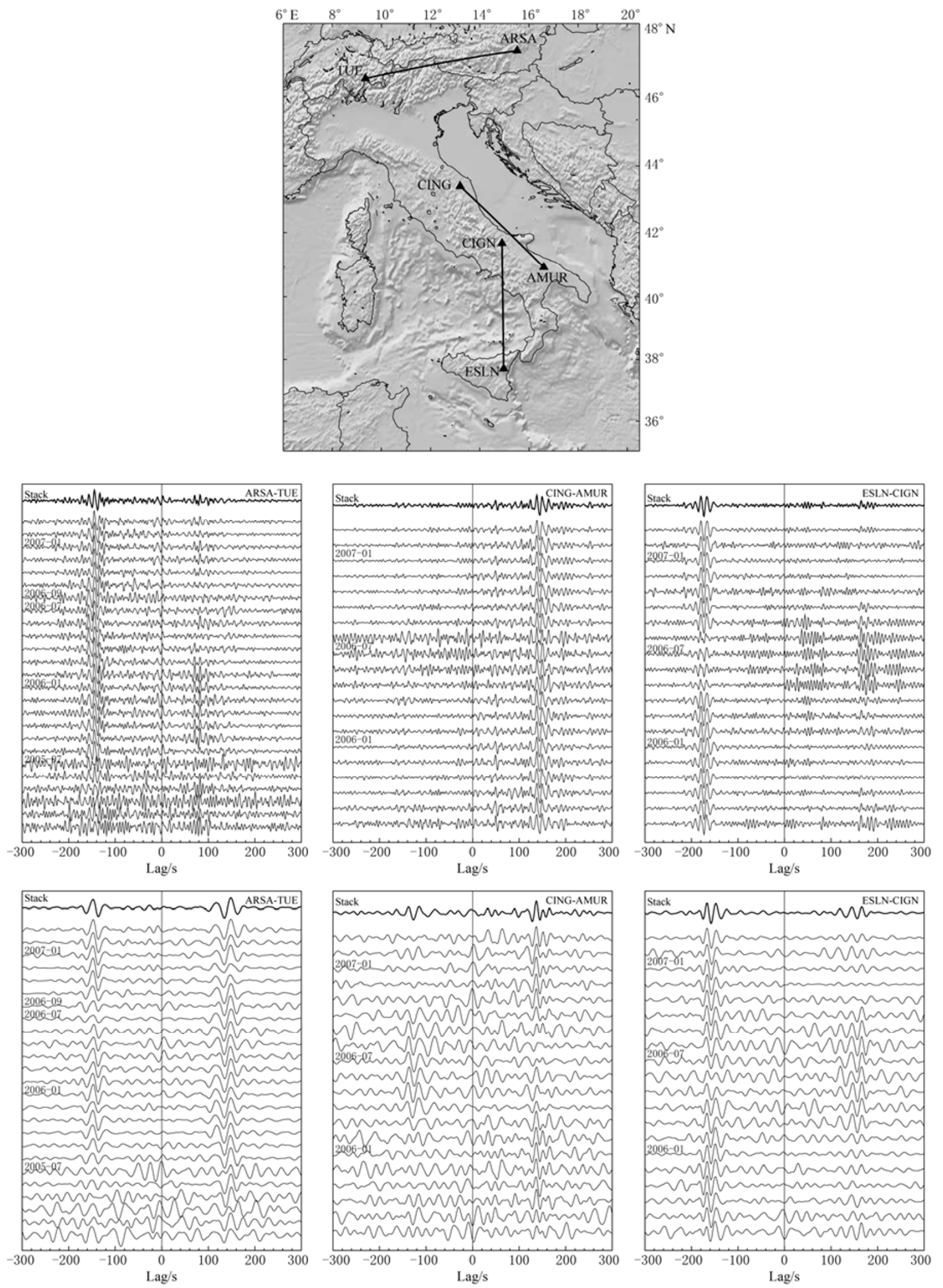

Figure 2 Monthly cross-correlations computed for three station-pairs: ARSA-TUE, CING-AMUR and ESLN-CIGN for frequency band $0.05-0.2 \mathrm{~Hz}$ (the middle row) and $0.02-0.05 \mathrm{~Hz}$ (the bottom row). The stacks over all the available months are displayed at the top of each panel. 
summer signals are mainly shown on negative/positive lag, however, in winter the situation is reversed, which may related to the noise generated in the Mediterranean sea and indicate that the noise recorded in summer in this area is dominated by surface waves generated from different locations compared with that recorded in winter.

Although the cross-correlations display non-symmetric and seasonal variations, they generally show coherent waveforms from month to month. Therefore, in order to simplify data analysis in this study, we separate each cross-correlation into positive and negative lags and then add the two lags to yield a symmetric cross-correlation, and more than 2000 station-pairs have been used. In Figure 3, we plot the distribution of dispersion measurements at different periods and the path coverage at $15 \mathrm{~s}$ and $30 \mathrm{~s}$. Since the path distribution is not even in the study area due to few available stations out of the Italian peninsula, path coverage is good within the Italian peninsula and becomes sparse toward the periphery.
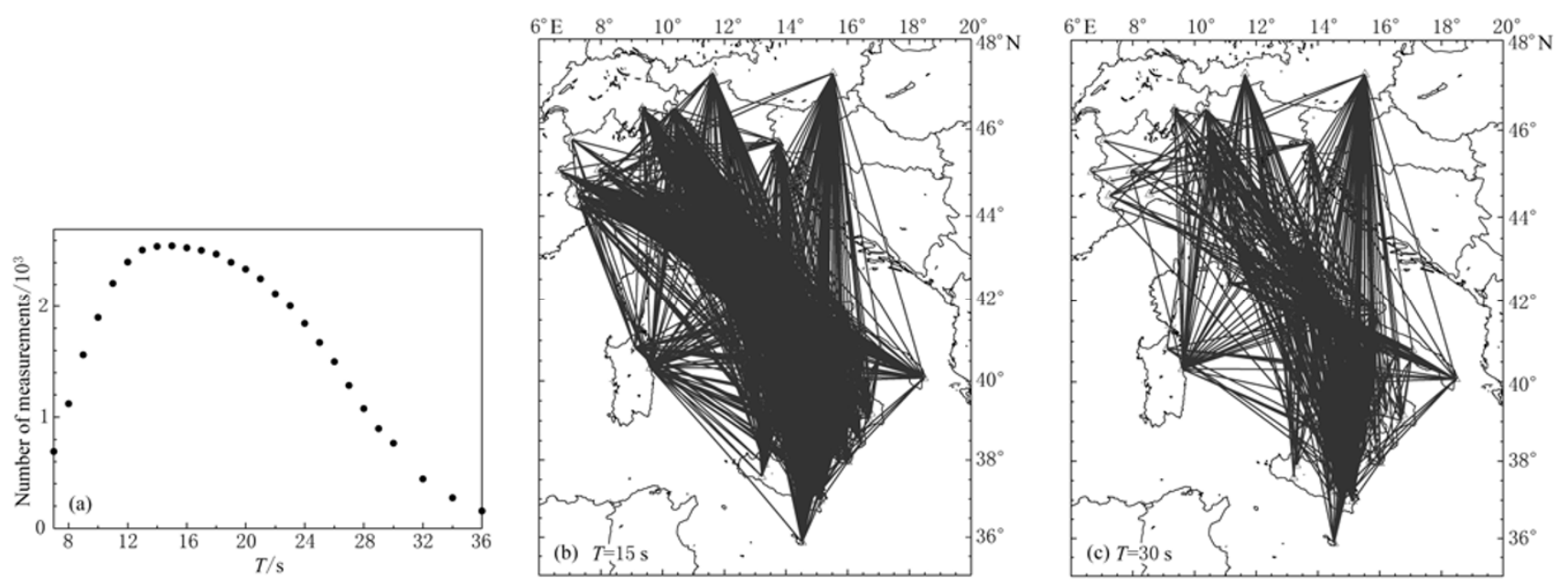

Figure 3 (a) Plot of dispersion measurements for different periods used in the inversion; (b) Ray path coverage at period $T=15 \mathrm{~s}$; (c) Ray path coverage at $T=30 \mathrm{~s}$.

In this study, dispersion was determined using multiple-filter analysis technique, and the tomographic work followed the conventional two-step scheme. In the first step, the Occam's inversion method (Constable et al., 1987; Huang et al., 2003) was used to invert for group velocities. Then in the second step the shear wave velocity structures beneath each grid node were individually inverted at all periods from group velocities. Since those techniques used in this paper are the same as those used in our previous work (Li et al., 2009, 2010), they will not be elaborated here. Before group velocity inversion, checkerboard tests were first made to estimate the achievable resolution. In the input model the velocity is alternatively 2.94 and $2.66 \mathrm{~km} / \mathrm{s}$ in $0.6^{\circ} \times 0.6^{\circ}$ blocks as shown in Figure 4a. Then synthetic data of group velocities were computed according to the actual paths at period $15 \mathrm{~s}$, and the resulting velocity image is given in Figure 4b. The resolving power is good beneath the Italian peninsula due to dense path coverage, but it becomes poor toward the surrounding area. Figure $4 \mathrm{c}$ displays the result of a similar test with the path cover- age at $30 \mathrm{~s}$. In that case, the theoretical velocity model has a $1.0^{\circ} \times 1.0^{\circ}$ checkerboard pattern and is not shown here. The overall reconstructed velocity map is correct for the Italian peninsula. Therefore, as a rough estimation, we put the resolution as $0.6^{\circ}$ for shorter periods and $1.0^{\circ}$ for longer periods.

Figure 5 shows the depth-sensitivity kernels for Love wave group velocity. It is well-known that surface waves at short periods usually tend to sample materials closer to the surface, whereas long periods are sensitive to faster velocities found deeper in the Earth. It can be seen from Figure 5 that Love waves at 8 and $15 \mathrm{~s}$ are more sensitive to the crustal structure shallower than 15 $\mathrm{km}$; for structure deeper than $20 \mathrm{~km}$, Love waves at 24 and $30 \mathrm{~s}$ show higher sensitivity.

Figure 6 displays the group velocity distributions of Love waves at periods $8,15,24$ and $30 \mathrm{~s}$ with blue color for high and red for low velocities. In the $8 \mathrm{~s}$ group velocity map (Figure 6a) the Po plain stands out as having a conspicuous low velocity. At $15 \mathrm{~s}$ period (Figure $6 \mathrm{~b})$, although the lowermost velocity persists beneath 

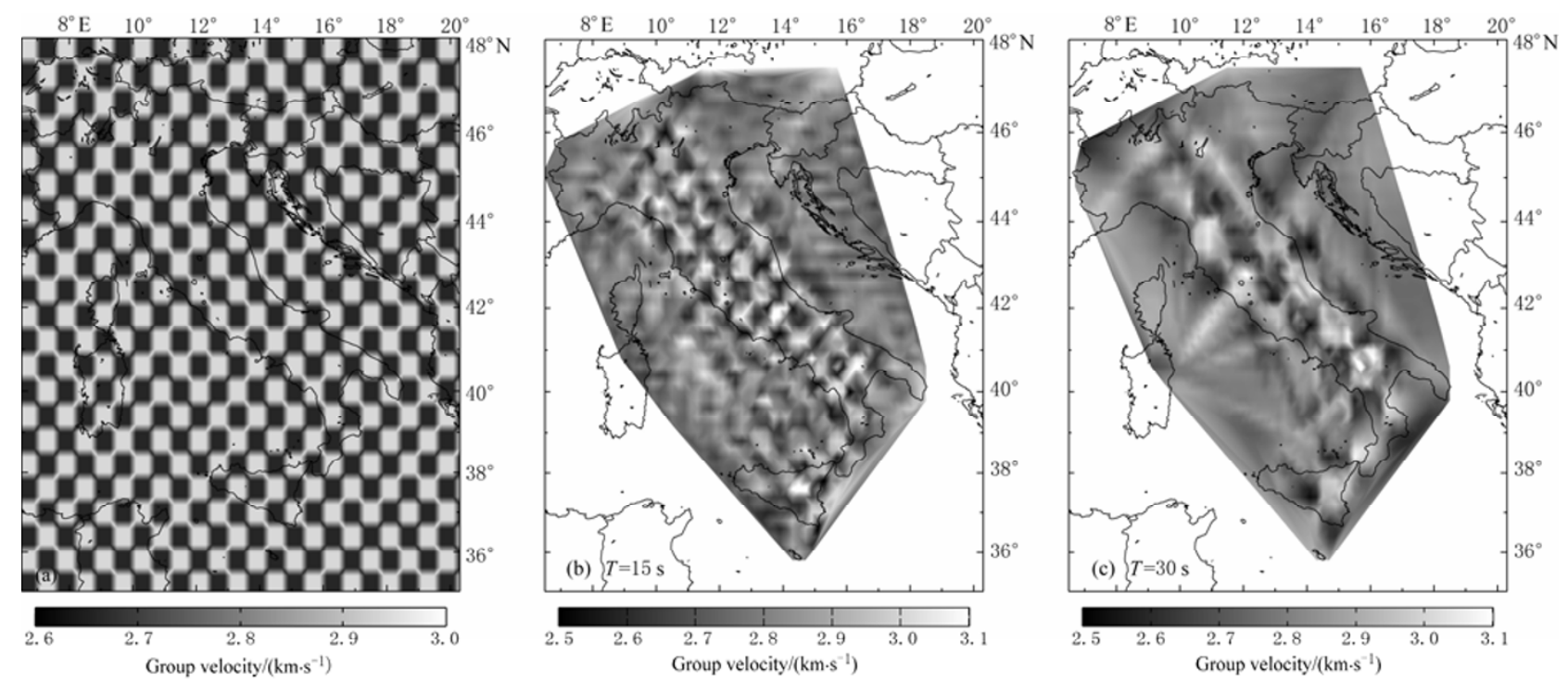

Figure 4 Checkerboard tests. (a) Theoretical model with $0.6^{\circ} \times 0.6^{\circ}$ blocks and alternatively input velocity 2.66 and 2.94 $\mathrm{km} / \mathrm{s}$; (b) Inversion result for period $T=15 \mathrm{~s}$ path coverage; (c) Inversion result for $T=30 \mathrm{~s}$ path coverage. Theoretical model $\left(1.0^{\circ} \times 1.0^{\circ}\right)$ is not shown here.

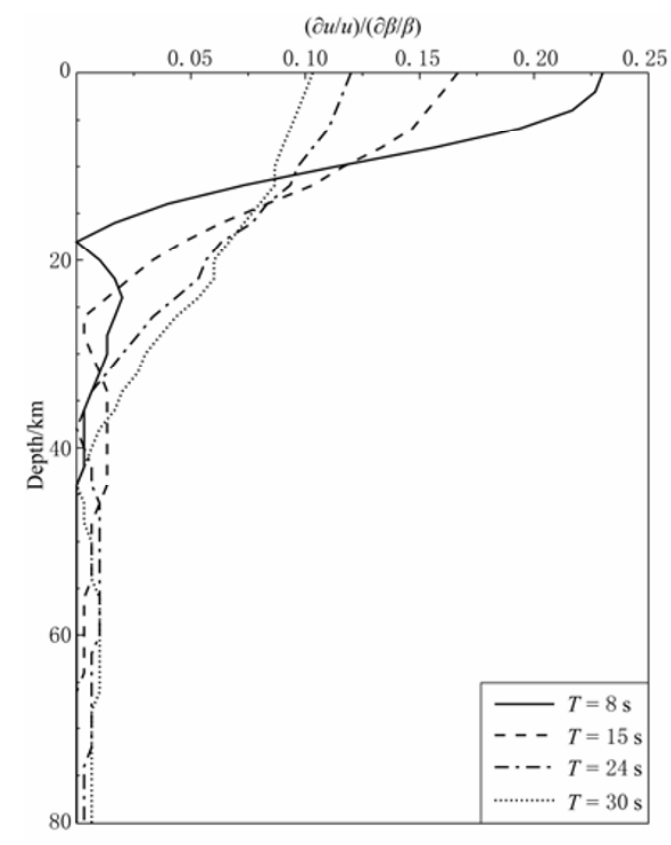

Figure 5 Depth sensitivity kernels to shear velocity for Love wave group velocity at periods $8,15,24$ and $30 \mathrm{~s}$.

the Po plain, the northern and central Apennines and Sicily are also resolved with low velocities. Meanwhile, it is evident that high velocities are centered in the Tyrrhenian sea. At $24 \mathrm{~s}$ period (Figure 6c), the velocity distribution is similar to those at $15 \mathrm{~s}$ except for Sicily no longer showing low velocities. In the $30 \mathrm{~s}$ map (Figure 6d), the distribution of low velocities beneath the Po plain widens to the central and eastern Alps, and high velocities occur beneath the Tyrrhenian sea and Sicily.

\section{Shear wave velocity structure}

Surface waves at different periods sample the Earth structure over different depth ranges, therefore, from the group velocity distribution we can get a rough estimation of the lateral variation of the shear wave velocity. In this study, we first extracted the pure path dispersion curves for each grid node based on Love wave group velocities obtained in the previous section, and then carried out inversions for shear wave (SH) velocity structure by using a program developed by Herrmann and Ammon (2004). The initial models consist of 50 layers with $1-\mathrm{km}$ thickness of each layer. The same initial model is used for all nodes in our inversion, then the inversion was repeated 15 times with 15 different initial models to reduce initial model's effect on our results, and the final $\mathrm{SH}$ velocity structure was determined by averaging all solutions.

Figure 7 shows shear wave velocity along three vertical profiles from the surface to $40 \mathrm{~km}$ depth. In the profile $A A^{\prime}$, it is evident that at depth between $8 \mathrm{~km}$ and $30 \mathrm{~km}$ shear wave velocities in the northern Tyrrhenian sea show higher speed than beneath the northern Apennines and the northern Adriatic sea, which are consistent with previous studies that a very thin oceanic crust and lithosphere are reported beneath the Tyrrhenian sea 

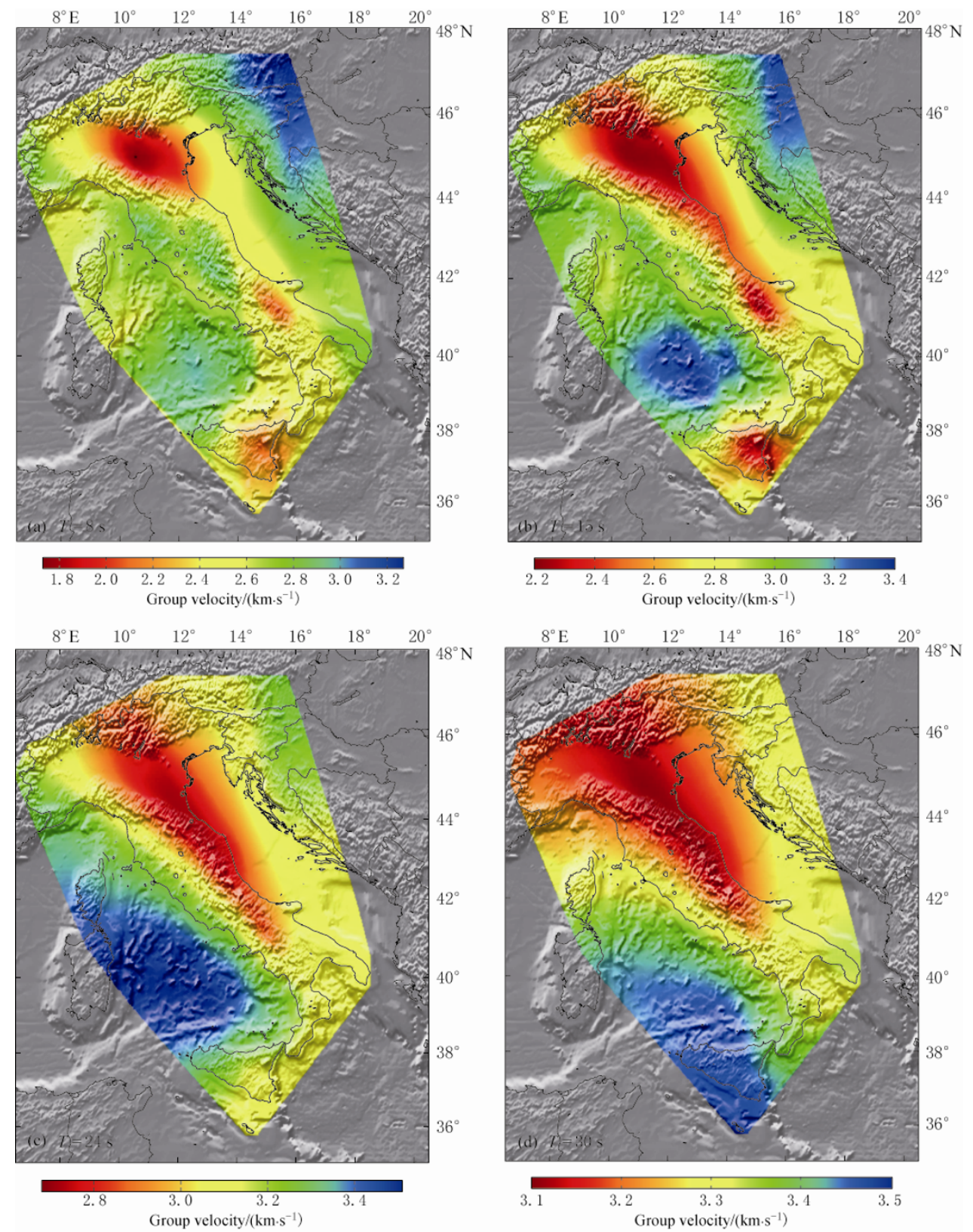

Figure 6 Estimated Love wave group velocity maps at periods of 8 (a), 15 (b), 24 (c) and $30 \mathrm{~s}$ (d). Period is indicated in the lower left corner of each map.

(Duschenes et al., 1986; Geiss, 1987; de Voogd et al., 1992; Pepe et al., 2000; Agostinetti and Amato, 2009), and normal continental crust beneath the Apennines and the Adriatic sea. The profile $B B^{\prime}$ crosses Sicily to the southern Apennines, and the lateral variation of velocities along the profile is still obvious. The Sicily island is featured with lower velocities at depth shallower than 5 $\mathrm{km}$, however, at depth around $20-30 \mathrm{~km}$, Sicily island show relatively high velocities. Along the profile $C C^{\prime}$ through the Po plain to the southern Apennines, at shal- low depth the lowest velocities are observed beneath the Po plain. At depth between $10 \mathrm{~km}$ and $20 \mathrm{~km}$, velocities beneath the Po plain and central-southern Apennines display higher speed than the northern Apennines.

\section{Discussion and conclusions}

Ambient noise Rayleigh wave tomography for the same region with the same analysis and inversion methods has been reported in our previous study (Li et al., 


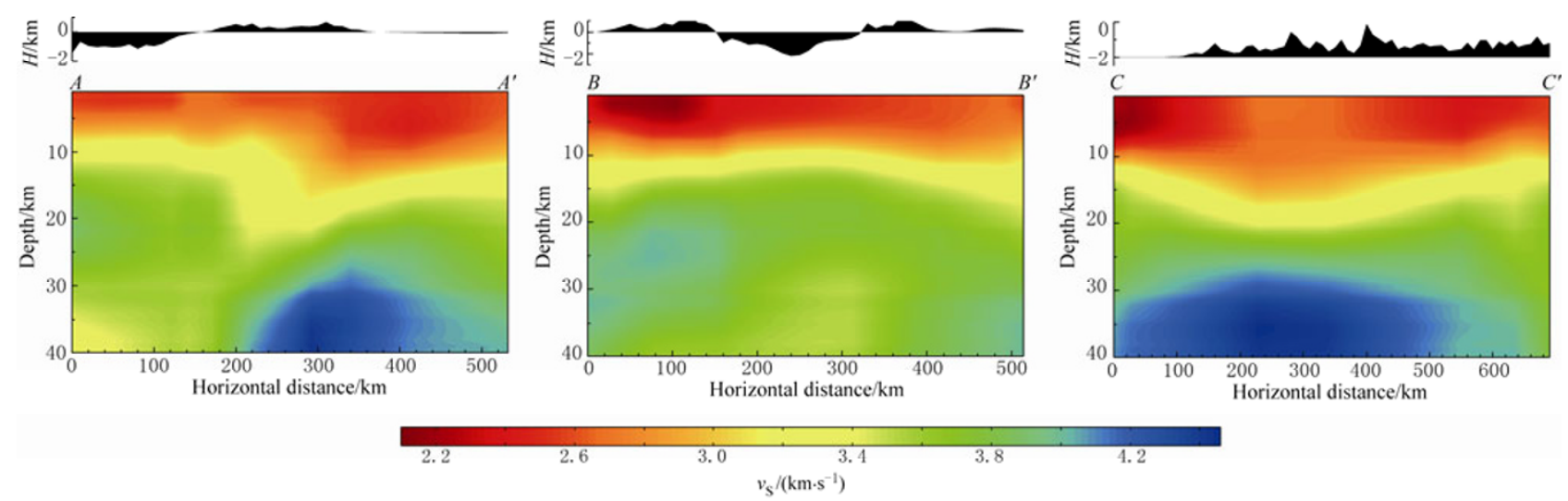

Figure 7 Vertical profiles of shear wave velocity along the lines $A A^{\prime}, B B^{\prime}$ and $C C^{\prime}$ in Figure 1. Topography ( $H$ denotes elevation) is plotted above each profile (black area).

2010). Our Love wave group velocity distribution is generally in agreement with that from Rayleigh wave data, and shows strong lateral velocity variation in the study area. At the short period $(<20 \mathrm{~s})$, surface wave velocities are dominantly sensitive to the upper crustal structure. Since sediments have much slower velocities than crystalline rocks, sedimentary basins usually appear as low-velocity anomalies at short-period. Low Rayleigh wave and Love wave group velocities at short periods mainly occurred beneath the Po plain, which likely indicates the thick alluvial basin of the Po river (Waldhauser et al., 1998; Kummerow et al., 2004; Di Stefano et al., 2009). High group velocities persist in the Tyrrhenian sea area from both Rayleigh wave and Love wave maps at period longer than $8 \mathrm{~s}$, which suggests a relatively thin crust in this area where a very thin oceanic crust has been reported by seismic sounding data (Duschenes et al., 1986; Geiss, 1987; de Voogd et al., 1992; Pepe et al., 2000). At long periods ( $>20$ s), surface waves become primarily sensitive to crustal thickness and the lower crustal and uppermost mantle structure. As seen in Figure 6, our Love wave group velocity maps exhibit an approximately inverse correlation with crustal thickness shown in Figure 8, with high velocities in regions with thin crust and low velocities in regions with thick crust. Meanwhile, our results show that although the Tyrrhenian sea and Adriatic sea are parts of the Mediterranean sea, the Tyrrhenian sea has a very thin oceanic crust while the Adriatic sea owns a normal continental crust.

Although our Love wave results are generally in agreement with results based on Rayleigh wave data, some differences still exist. For example, beneath the Apennines the SV velocity structure derived from Ray-

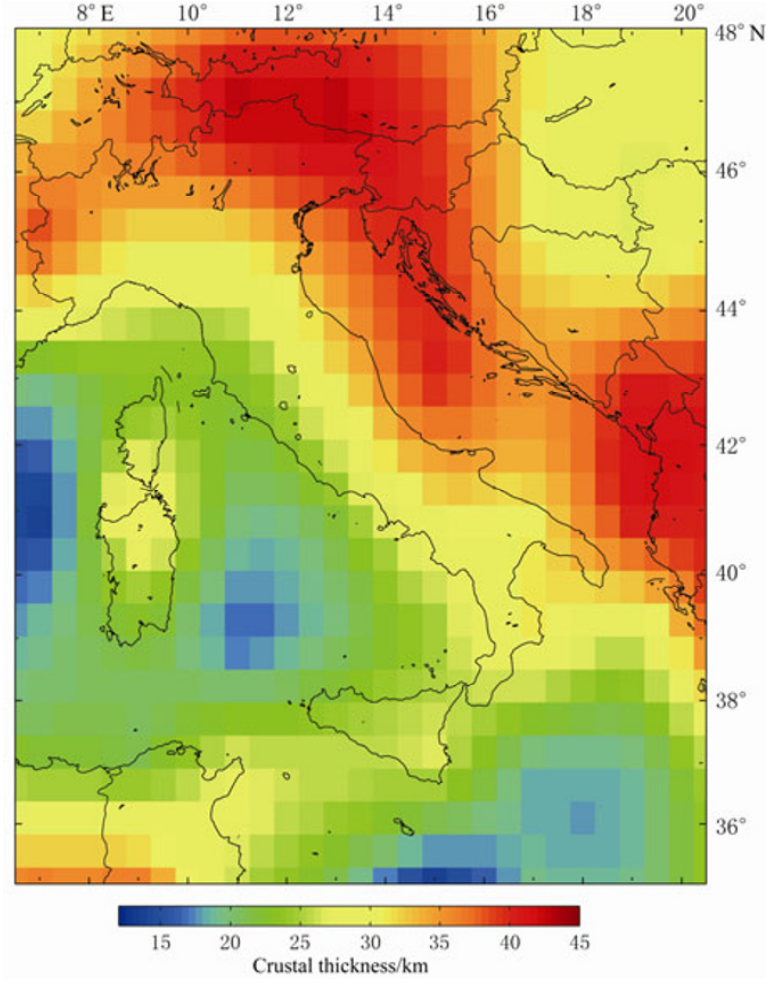

Figure 8 Maps of crustal thickness which is taken from CRUST2.0 (Bassin et al., 2000).

leigh shows a low-velocity patch between the depth 10 $\mathrm{km}$ and $30 \mathrm{~km}$, which is not seen in the SH velocity structure based on Love wave data. The sources of the differences require further studies.

In summary, this study has performed surface wave tomography of Italy by using seismic ambient noise data from 114 seismic stations to construct Love wave group velocity maps in the period range between $8 \mathrm{~s}$ and $34 \mathrm{~s}$. Cross-correlations are computed in one-hour segments 
with a duration ranging between 3 months and 1.5 years. The lateral resolution in the Italian peninsula and Tyrrhenian sea is estimated to be about $0.6^{\circ}-1.0^{\circ}$. The large velocity variation suggests strong heterogeneities and structure complexities in Italy. Our Love wave group velocity maps show that the overall velocity distribution pattern correlates well with surface geology and tectonic features, and are generally consistent with previous surface wave studies and ambient noise study based on Rayleigh wave: sedimentary basins are characterized with low velocity at shallow depth, and the Tyrrhenian sea is characterized with higher velocity below $8 \mathrm{~km}$ due to its thin oceanic crust.

Acknowledgments We thank the Centro Nazionale Terremoti (CNT) of INGV, MedNet and ZAMG data center for providing the data. We are thankful to the editor Xiaodong Song and two anonymous reviewers for their constructive comments to improve the manuscript. This research was supported in part by the 2004-2006 National Civil Defense Project of Italy (DPC)-S4, 2007-2009 DPC-S3 and the Fundamental Research Funds for the Central Universities of China under grant No. 2010ZD06.

\section{References}

Agostinetti N P and Amato A (2009). Moho depth and $v_{\mathrm{P}} / v_{\mathrm{S}}$ ratio in peninsular Italy from teleseismic receiver functions. $J$ Geophys Res 114: B06303, doi:10.1029/2008JB005899.

Bassin C, Laske G and Masters G (2000). The current limits of resolution for surface wave tomography in North America. EOS, Trans Am Geophys Un 81: F897.

Bensen G D, Ritzwoller M H and Shapiro N M (2008). Broadband ambient noise surface wave tomography across the United States. J Geophys Res 113: B05306, doi:10.1029/2007 JB005248.

Constable S C, Parker R L and Constable C G (1987). Occam's inversion: A practical algorithm for generating smooth models from electromagnetic sounding data. Geophysics 52: 289300 .

Derode A, Larose E, Tanter M, de Rosny J, Tourim A, Campillo $M$ and Fink M (2003). Recovering the Green's function from field-field correlations in an open scattering medium. J Acoust Soc Am 113: 2 973-2 976.

de Voogd, Truert B C, Chamot-Rooke N, Huchon P, Lallemant S and Le Pichon X (1992). Two-ships deep seismic soundings in the basin of the eastern Mediterranean Sea (Pasiphae cruise). Geophys J Int 109: 536-552.

Dewey J F, Helman M L, Turco E, Hutton D W H and Knott S P (1989). Kinematics of the western Mediterranean. In: Coward M P, Dietrich D and Park R G eds. Alpine Tectonics. Geol Soc Lond Spec Publ 45: 265-283.
Di Stefano R, Kissling E, Chiarabba C, Amato A and Giardini D (2009). Shallow subduction beneath Italy: Three-dimensional images of the Adriatic-European-Tyrrhenian lithosphere system based on high-quality $\mathrm{P}$ wave arrival times. J Geophys Res 114: B05305, doi:10.1029/2008JB005641.

Duschenes J, Sinha M C and Louden K E (1986). A seismic refraction experiment in the Tyrrhenian Sea. Geophys $J R$ astr Soc 85: 139-160.

Friedrich A, Krüger F and Klinge K (1998). Ocean-generated microseismic noise located with the Gräfenberg array. $J$ Seismol 2: 47-64.

Geiss E (1987). A new compilation of crustal thickness in the Mediterranean area. Ann Geophys 5B(6): 623-630.

Gvirtzman Z and Nur A (2001). Residual topography, lithospheric structure and sunken slabs in the central Mediterranean. Earth Planet Sci Lett 187: 117-130.

Herrmann R B and Ammon C J (2004). Surface waves, receiver functions and crustal structure. In: Computer Programs in Seismology. Version 3.30. Saint Louis University, http://www. eas.slu.edu/People/RBHerrmann/CPS330.html,

Huang Z, Su W, Peng Y, Zheng Y and Li H (2003). Rayleigh wave tomography of China and adjacent regions. $J$ Geophys Res 108(B2): 2 073, doi:10.1029/2001JB001696.

Kummerow J, Kind R, Oncken O, Giese P, Ryberg T, Wylegalla K, Scherbaum F and TRANSALP Working Group (2004). A natural and controlled source seismic profile through the Eastern Alps: TRANSALP. Earth Planet Sci Lett 225: 115-129.

Li H, Michelini A, Zhu L, Bernardi F and Spada M (2007). Crustal velocity structure in Italy from analysis of regional seismic waveforms. Bull Seismol Soc Am 97: 2 024-2 039.

Li H, Bernardi F and Michelini A (2010). Surface wave dispersion measurements from ambient seismic noise analysis in Italy. Geophys J Int 180: 1 242-1 252.

Li H, Su W, Wang C and Huang Z (2009). Ambient noise Rayleigh wave tomography in western Sichuan and eastern Tibet. Earth Planet Sci Lett 282: 201-211.

Liang C and Langston C A (2008). Ambient seismic noise tomography and structure of eastern North America. J Geophys Res 113: B03309, doi:10.1029/2007JB005350.

Lin F, Ritzwoller M H, Townend J, Bannister S and Savage M K (2007). Ambient noise Rayleigh wave tomography of New Zealand. Geophys J Int 72: 649-666, doi:10.1111/j.1365246X.2007.0341.x.

Malinverno A and Ryan W B F (1986). Extension in the Tyrrhenian Sea and shortening in the Apennines as a result of arc migration driven by sinking of the lithosphere. Tectonics $\mathbf{5}$ : 227-245.

Mantovani E, Nolet G and Panza G F (1985). Lateral heterogeneity in the crust of the Italian region from regionalized Rayleigh wave group velocities. Ann Geophys 3: 519-530.

Margheriti L, Lucente F P and Pondrelli S (2003). SKS splitting measurements in the Apennine-Tyrrhenian domain Italy and their relation with lithospheric subduction and mantle convection. J Geophys Res 108(B4): 2 218, doi:10.1029/2002JB 001793. 
Marzorati S and Bindi D (2006). Ambient noise levels in north central Italy. Geochem Geophys Geosyst 7: Q09010, doi:10. 1029/2006GC001256.

Marzorati S and Bindi D (2008). Characteristics of ambient noise cross correlations in northern Italy within the frequency range of 0.1-0.6 Hz. Bull Seismol Soc Am 98: 1389-1 398.

Panza G, Mueller S and Calcagnile G (1980). The gross features of the lithosphere-asthenosphere system in Europe from seismic surface waves and body waves. Pure Appl Geophys 118: 1209-1213.

Patacca E and Scandone P (1989). Post-Tortonian mountain building in the Apennines. The role of the passive sinking of a relic lithospheric slab. In: Boriani A, Bonafede M, Piccardo G $\mathrm{B}$ and Vai $\mathrm{G} \mathrm{B}$ eds. The Lithosphere in Italy. Academia Nazionale dei Lincei, Rome, 157-176.

Patacca E, Sartori R and Scandone P (1990). Tyrrhenian Basin and Apenninic Arcs: kinematic relations since Late Tortonian times. Mem Soc Geol Ital 45: 425-451.

Pedersen H, Kruger F and the SVEKALAPKO Seismic Tomography Working Group (2007). Influence of the seismic noise characteristics on noise correlations in the Baltic Shield. Geophys J Int 168: 197-210.

Pepe F, Bertotti G, Cella F and Marsella E (2000). Rifted margin formation in the south Tyrrhenian Sea: a high-resolution seismic profile across the north Sicily passive continental margin. Tectonics 19(2): 241-257.

Pontevivo A and Panza G (2002). Group velocity tomography and regionalization in Italy and bordering areas. Phys Earth Planet Int 52: 193-203.
Sabra KG, Gerstoft P, Roux P, Kuperman W A and Fehler M C (2005). Surface wave tomography from microseism in southern California. Geophys Res Lett 32: L14311, doi:10.1029/ 2005 GL023155.

Shapiro N M, Campillo M, Stehly L and Ritzwoller M H (2005). High-resolution surface-wave tomography from ambient seismic noise. Science 307: 1615-1 618.

Stehly L, Campillo M, Shapiro N M, Guilbert J, Boschi L and Giardini D (2009). Tomography of the Alpine region from observations of seismic ambient noise. Geophys J Int 178: 338-350.

Waldhauseret F, Kissling E, Ansorge J and Mueller S (1998). Three-dimensional interface modeling with two-dimensional seismic data: the Alpine crust-mantle boundary. Geophys J Int 135: 264-278.

Weaver R L and Lobkis O I (2004). Diffuse fields in open system and the emergence of the Green's function. J Acoust Soc Am 110: 2731-2 734 .

Westaway R (1990). Present-day kinematics of the plate boundary zone between African and Europe, from the Azores to the Aegean. Earth Planet Sci Lett 96: 393-406.

Yang Y, Ritzwoller M H, Levshin A L and Shapiro N M (2007). Ambient noise Rayleigh wave tomography across Europe. Geophys J Int 168: 259-274.

Yao H, Beghein C and van der Hilst R D (2008). Surface wave array tomography in SE Tibet from ambient seismic noise and two-station analysis: - II. Crustal and upper-mantle structure. Geophys J Int 173: 205-219, doi:10.1111/j.1365-246X.2007. 03696.x. 